\title{
Lifestyle behaviors changes during the COVID-19 pandemic quarantine among 6,881 Brazilian adults with depression and 35,143 without depression
}

\author{
Mudanças de comportamentos saudáveis durante a quarentena \\ por conta da pandemia do COVID-19 entre 6.881 adultos \\ brasileiros com depressão e 35.143 sem depressão
}

\author{
André Oliveira Werneck (https://orcid.org/0000-0002-9166-4376) ${ }^{1}$ \\ Danilo Rodrigues da Silva (https://orcid.org/0000-0003-3995-4795) ${ }^{2}$ \\ Deborah Carvalho Malta (https://orcid.org/0000-0002-8214-5734) ${ }^{3}$ \\ Paulo Roberto Borges de Souza-Júnior (https://orcid.org/0000-0002-8142-4790) ${ }^{4}$ \\ Luiz Otávio Azevedo (https://orcid.org/0000-0002-4876-5948) ${ }^{4}$ \\ Marilisa Berti de Azevedo Barros (https://orcid.org/0000-0003-3974-195X) ${ }^{5}$ \\ Célia Landmann Szwarcwald (https://orcid.org/0000-0002-7798-2095) ${ }^{4}$
}

${ }^{1}$ Departamento de Nutrição, Faculdade de Saúde Pública, Universidade de São Paulo. Av. Dr. Arnaldo 715, Cerqueira César. 01246-904 São Paulo SP Brazil.

andrewerneck@usp.br ${ }^{2}$ Departamento de

Educação Física, Universidade Federal de Sergipe. São Cristóvão SE Brazil.

${ }^{3}$ Departamento de Enfermagem MaternoInfantil e Saúde Pública, Escola de Enfermagem, Universidade Federal de Minas Gerais. Belo Horizonte MG Brazil. ${ }^{4}$ Instituto de Comunicação e Informação Científica e Tecnológica em Saúde, Fiocruz. Rio de Janeiro RJ Brazil.

${ }^{5}$ Departamento de Saúde Pública, Faculdade de Ciências Médicas, Universidade Estadual de Campinas. Campinas SP Brazil.

\begin{abstract}
Our aim was to analyze the association between previously diagnosed lifetime depression and changes in physical activity (PA), TV-viewing, consumption of fruits and vegetables as well as frequency of ultra-processed food (UPF) consumption. Data of 41,923 Brazilian adults $(6,881$ with depression and 35,042 without depression) were used. Participants reported PA ( $\geq 150 \mathrm{~min} /$ week), $T V$-viewing ( $\geq 4 \mathrm{~h} /$ day), frequency of eating fruits or vegetables $(\leq 4$ days/week) and UPF ( $\geq 5$ days/week). For incidence indicators, we only considered participants without the risk behavior before the quarantine. People without and with depression presented, respectively, incidence of physical inactivity [70.1\% (95\% CI: 67.4-72.8) vs 76.3 (70.3-81.5)], high TV-viewing [31.2 (29.632.8) vs 33.9 (30.5-37.4)], low frequency of fruit or vegetable consumption [28.3 (25.8-31.0) vs 31.5 (26.1-37.5)] and elevated frequency of UPF consumption [9.7 (8.9-10.7) vs 15.2 (13.0-17.7)]. Participants with depression were more likely to present elevated frequency of UPF consumption incidence [OR:1.49 (95\%CI:1.21-1.83)]. Thus, participants with previous diagnosis of depression were at risk for incidence of unhealthy diet behaviors.
\end{abstract}

Key words Exercise, Diet, Mental disorders
Resumo Nosso objetivo foi analisar a associação entre depressão previamente diagnosticada e alterações na atividade fisica $(A F)$, tempo assistindo $T V$, consumo de frutas e vegetais, bem como na frequência do consumo de alimentos ultraprocessados (AUP). Foram utilizados dados de 41.923 adultos brasileiros (6.881 com depressão e 35.042 sem depressão) de uma pesquisa de comportamentos em âmbito nacional. Os participantes relataram a prática de $A F(\geq 150 \mathrm{~min} / \mathrm{semana})$, tempo de TV ( $\geq 4 \mathrm{~h} / \mathrm{dia}$ ), frequência de consumo de frutas ou vegetais ( $\leq 4$ dias/semana) e AUP $(\geq$ 5 dias/semana). Para indicadores de incidência, consideramos apenas participantes sem o comportamento de risco antes da quarentena. Pessoas sem e com depressão apresentaram, respectivamente, incidência de inatividade física [70,1\% (IC95\%: 67,4-72,8) vs 76,3 (70,3-81,5)], elevado tempo assistindo TV [31,2 (29,6-32,8) vs 33,9 (30,537,4)], baixa frequência de consumo de frutas ou vegetais $[28,3(25,8-31,0)$ vs $31.5(26.1-37.5)] e$ frequência elevada de AUP $[9,7(8,9-10,7)$ vs 15,2 (13,0-17,7)]. Pessoas com diagnóstico prévio de depressão apresentaram maior probabilidade de incidência de elevado consumo de AUP [OR:1,49 (IC95\%:1,21-1,83)]. Portanto, participantes com diagnóstico prévio de depressão apresentam maior risco de incidência de comportamentos alimentares não saudáveis.

Palavras-chave Exercício, Dieta, Transtornos mentais 


\section{Introduction}

Considering the fast spread of new coronavirus (COVID-19) pandemics, social distancing measures as quarantines are recommended to reduce the infection rates ${ }^{1}$. The Brazilian ministry of health has been recommending social distancing since early March (2020) and several Brazilian states declared quarantine period. The quarantine, in turn, has be associated with unhealthy behaviors, such as physical inactivity, sedentary behavior ${ }^{2,3}$ and poor dietary habits ${ }^{2,4}$. However, quarantines tend do not affect population equally. People with mental disorders, who were already at risk for the development of unhealthy behaviors before the pandemic ${ }^{5,6}$, can be more affected by the pandemic period compared to the general population.

In this sense, it is also noted that people with mental disorders and illness are at higher risk to increase psychological distress and its complications during quarantine periods $s^{7,8}$. Therefore, we aimed to analyze the association between previously diagnosed lifetime depression and changes in physical activity, TV-viewing, consumption of fruits and vegetables as well as frequency of ultra-processed food consumption.

\section{Methods}

\section{Sample}

The "Brazilian behavioral research during the COVID-19 pandemic" was a national cross-sectional health survey, with retrospective information. Data collection was conducted between April 24th and May 24th, 2020. The invitation of participants was through a chain sampling procedure. In the first stage, the 15 researchers involved in the study chose a total of 200 other researchers from different states in Brazil. Also, each researcher in the study chose 20 people from their social network, making a total of 4,000 people chosen. The people chosen in the first stage were called as influencers. These sent the survey link to at least 12 people from their social networks, obeying a stratification by sex, age range (18-39; 40-59; 60+) and education level (incomplete high school or less; education complete medium or more). In addition, information about the study was disseminated through press releases, social communications from participating research institutions, state health departments, and social media. All procedures were approved by the Comissão Nacional de Ética em Pesquisa (Conep). The initial sample was composed of 45,160 participants. Due to missing data, the final sample was composed of 41,923 adults $(6,881$ with depression and 35,042 without depression). The sample was weighted according to characteristics from the National Household Sample Survey (2019), considering the population in each state, education, age, sex, and prevalence of chronic diseases, aiming to let the sample nationally representative.

\section{Previous diagnosis of depression}

Previous diagnosis of depression was assessed through a question regarding the lifetime diagnosis of depression by a physician. The response options were either yes or no.

\section{Physical activity incidence}

Physical activity was estimated asking about the frequency and duration of leisure-time physical activities before and during the quarantine period and classified using the cut-off point of $150 \mathrm{~min} /$ week $^{9}$. For the analyzes purposes (incidence), we only classified those without physical inactivity before the COVID-19 pandemic quarantine.

\section{TV-viewing incidence}

TV-viewing was assessed asking about time watching TV before and during the COVID-19 pandemic quarantine, with a cut-off point of 4 $\mathrm{h} /$ day. For the analyzes purposes (incidence), we only classified those without elevated TV-viewing before the COVID-19 pandemic quarantine.

\section{Low fruit or vegetables and elevated frequency of ultra-processed food consumption}

Ultra-processed food and fruit and vegetable consumption were assessed asking about the frequency of eating fruits, vegetables, sugary foods, snacks, ready-to-eat frozen foods and embedded foods before and during the COVID-19 pandemic quarantine. We classified as risk behavior those reporting less than 5 days per week eating fruits or vegetables as well as eating five or more days per week at least one ultra-processed food (sugary foods, snacks, ready-to-eat frozen foods and embedded foods), which were classified according the NOVA classification ${ }^{10}$. For the analyzes 
purposes (incidence), we only classified those without elevated frequency of ultra-processed food consumption before the COVID-19 pandemic quarantine for ultra-processed food analysis and those without low frequency of fruit and vegetable consumption before the quarantine for fruit and vegetable analysis.

\section{Covariates}

We used sex, age group, highest academic achievement, working status during the pandemic, skin color, alcohol use, tobacco smoking, diagnoses of COVID-19 on a close friend, co-worker or relative and adherence to the quarantine as covariates. The highest academic achievement was classified as no academic achievement or elementary school, high school and higher education or more. Working status during the quarantine was classified as currently not working, working on a normal routine and home office. Skin color was classified as white or other. Diagnoses of COVID-19 on a close friend, co-worker or relative was assessed through the question through a binary question. The adherence to the quarantine was assessed and we classified as positive for quarantine adherence those reporting that $I$ stayed at home just going shopping at the supermarket and pharmacy or stayed strictly at home, leaving only for health care needs.

\section{Statistics}

Characteristics of the sample were described using frequencies and 95\% confidence intervals. Non-crossed 95\% confidence intervals were used were used to compare participants with and without previous diagnosis of depression ${ }^{11}$. We used incidence of physical inactivity, high TV-viewing, low consumption of fruits or vegetables and elevated ultra-processed food as outcomes (only considering those who did not report the risk behavior before the quarantine). Therefore, we created crude and adjusted logistic regression models to analyze the association between previous diagnoses of depression and incidence of lifestyle risky behaviors during the COVID-19 quarantine. The analyzes were weighted according to characteristics from the National Household Sample Survey (2019), which make our findings nationally representative of Brazilian adults. All analyses were conducted using the software Stata 15.1 .

\section{Results}

Characteristics of the sample in people with and without previous diagnosis of depression are presented on Table 1. The women presented a higher prevalence of previous diagnosis of depression. Also, people with previous diagnosis of depression presented higher prevalence of physical inactivity, low fruit and vegetables ingestion and elevated frequency of ultra-processed food consumption. Both the general population (without depression) and people with depression, respectively, presented a considerable incidence of physical inactivity [70.1\% (95\%CI: 67.4 to 72.8 ) vs $76.3 \%$ (95\%CI: 70.3 to 81.5 )], high TV-viewing [31.2\% (95\%CI: 29.6 to 32.8) vs $33.9 \%$ (95\%CI: 30.5 to 37.4 )], low frequency of fruit or vegetable consumption $[28.3 \%(95 \% \mathrm{CI}$ : 25.8 to 31.0 ) vs $31.5 \%$ (95\%CI: 26.1 to 37.5 )] and elevated frequency of ultra-processed food consumption [ $9.7 \%$ (95\%CI: 8.9 to 10.7 ) vs $15.2 \%$ (95\%CI: 13.0 to 17.7 )].

Table 2 shows the association between previous diagnoses of depression and incidence lifestyle behaviors change during the COVID-19 quarantine. Adjusted analyzes revealed that people with depression were $49 \%$ more likely to elevated frequency of ultra-processed food consumption incidence [OR: 1.49 (95\%CI: 1.21 to $1.83)$, when compared with people without depression. However, incidence of physical inactivity, high TV-viewing and low frequency of fruit or vegetable consumption were not different among people with depression, comparing with the general population.

\section{Discussion}

We investigated whether people with previous diagnosis of depression presented higher incidence of unhealthy health behaviors during the COVID-19 pandemic quarantine in Brazilian adults. Our main findings were that both adults with and without depression presented considerable incidence of unhealthy behaviors. However, participants with previous diagnosis of depression were more likely to present incidence of elevated frequency of ultra-processed food consumption.

Women presented a higher prevalence of previous diagnosis of depression, which is consistent with previous national studies, such as the Brazilian National Health Survey ${ }^{12}$. Also, our findings were in line with previous findings of reductions in health behaviors during the quarantine in oth- 
Table 1. Characteristics of the sample $(n=41,923)$.

\begin{tabular}{|c|c|c|}
\hline Variables & $\begin{array}{c}\text { Without depression } \\
(\mathrm{n}=35,042) \%(95 \% \mathrm{CI}) \\
\end{array}$ & $\begin{array}{c}\text { With depression } \\
(\mathrm{n}=6,881) \%(95 \% \mathrm{CI})\end{array}$ \\
\hline Sex (women) & $50.8(49.1$ to 52.4$)$ & $68.2(64.3$ to 71.8$)$ \\
\hline \multicolumn{3}{|l|}{ Age group } \\
\hline $18-39$ & $48.2(46.5$ to 49.5$)$ & $51.8(48.3$ to 55.3$)$ \\
\hline $40-59$ & $33.2(31.7$ to 34.7$)$ & $35.3(32.1$ to 38.6$)$ \\
\hline $60+$ & $18.6(17.3$ to 20.1$)$ & $12.9(10.7$ to 15.5$)$ \\
\hline \multicolumn{3}{|l|}{ Highest academic achievement } \\
\hline No academic achievement or elementary school & $9.9(8.9$ to 11.1$)$ & $8.7(6.8$ to 11.1$)$ \\
\hline High school & $72.9(71.6$ to 74.0$)$ & $73.0(70.4$ to 75.4$)$ \\
\hline More than high school & $17.2(16.6$ to 17.9$)$ & $18.3(17.0$ to 19.7$)$ \\
\hline \multicolumn{3}{|l|}{ Working status during the quarantine } \\
\hline Not working & $52.7(51.1$ to 54.4$)$ & $58.5(54.9$ to 61.9$)$ \\
\hline Normal routine & $21.7(20.3$ to 23.2$)$ & $17.3(14.4$ to 20.7$)$ \\
\hline Home office & $25.6(24.2$ to 27.0$)$ & $24.2(21.5$ to 27.1$)$ \\
\hline Skin color (non-white) & $55.2(53.6$ to 56.7$)$ & $46.2(42.7$ to 49.8$)$ \\
\hline Diagnoses of COVID-19 on a relative or close friend & $16.4(15.3$ to 17.5$)$ & $18.5(16.0$ to 21.3$)$ \\
\hline Quarantine adherence (yes) & 73.5 (72.0 to 74.9$)$ & $77.0(73.2$ to 80.4$)$ \\
\hline Physical inactivity before & $68.8(67.3$ to 70.3$)$ & $75.5(72.5$ to 78.3$)$ \\
\hline Physical inactivity during & $87.4(86.3$ to 88.4$)$ & $92.0(90.2$ to 93.5$)$ \\
\hline High TV-viewing before & $10.2(9.1$ to 11.3$)$ & $9.8(8.2$ to 11.7$)$ \\
\hline High TV-viewing during & $37.4(35.8$ to 39.0$)$ & $39.6(36.3$ to 43.0$)$ \\
\hline Low frequency of fruit or vegetables before & $77.5(76.2$ to 78.8$)$ & $81.6(79.2$ to 83.8$)$ \\
\hline Low frequency of fruit or vegetables during & $78.1(76.2$ to 78.8$)$ & $81.6(78.8$ to 83.8$)$ \\
\hline Elevated frequency of ultra-processed food before & $13.3(12.2$ to 14.4$)$ & $17.7(15.2$ to 20.4$)$ \\
\hline Elevated frequency of ultra-processed during & $17.6(16.4$ to 18.8$)$ & $24.6(22.0$ to 27.4$)$ \\
\hline \multicolumn{3}{|l|}{ Incidence of (During the quarantine): } \\
\hline Physical inactivity & $70.1(67.4$ to 72.8$)$ & $76.3(70.3$ to 81.5$)$ \\
\hline High TV-viewing** & $31.2(29.6$ to 32.8$)$ & $33.9(30.5$ to 37.4$)$ \\
\hline Low fruit or vegetable consumption ${ }^{\star * *}$ & $28.3(25.8$ to 31.0$)$ & $31.5(26.1$ to 37.5$)$ \\
\hline Elevated ultra-processed food consumption ${ }^{\star * \star \star}$ & 9.7 (8.9 to 10.7$)$ & $15.2(13.0$ to 17.7$)$ \\
\hline
\end{tabular}

Table 2. Association between previous diagnoses of depression and incidence lifestyle behaviors change during the COVID-19 quarantine.

\begin{tabular}{|c|c|c|c|c|}
\hline & \multicolumn{4}{|c|}{ Incidence } \\
\hline & $\begin{array}{l}\text { Physical inactivity } \\
\text { OR }(95 \% \mathrm{CI})\end{array}$ & $\begin{array}{l}\text { High TV-viewing } \\
\text { OR }(95 \% \mathrm{CI})\end{array}$ & $\begin{array}{c}\text { Low fruit or vegetable } \\
\text { consumption } \\
\text { OR }(95 \% \mathrm{CI}) \\
\end{array}$ & $\begin{array}{c}\text { Elevated ultra-processed } \\
\text { food consumption } \\
\text { OR }(95 \% \mathrm{CI})\end{array}$ \\
\hline Crude model & 1.37 (0.98 to 1.92$)$ & $1.13(0.95$ to 1.34$)$ & $1.17(0.87$ to 1.57$)$ & $1.66(1.35$ to 2.04$)$ \\
\hline Adjusted model & $1.24(0.86$ to 1.78$)$ & $1.09(0.92$ to 1.29$)$ & $1.04(0.77$ to 1.40$)$ & $1.49(1.21$ to 1.83$)$ \\
\hline \multicolumn{5}{|c|}{$\begin{array}{l}\text { Note. Adjusted for sex, age group, highest academic achievement, working status during the quarantine, skin color, diagnoses } \\
\text { of COVID-19 on a relative or close friend and quarantine impact. OR, odds ratio. CI, confidence interval. Sample size for each } \\
\text { analysis only considered those participants without the health behavior before the quarantine: Physical inactivity (without } \\
\text { depression: } 13,242 \text {, with depression: 1,997); High TV-viewing (without depression: } 32,278 \text {, with depression: 6,244); Low fruit or } \\
\text { vegetable consumption (without depression: 11,709, with depression: 1,936); Elevated ultra-processed food (without depression: } \\
\text { 30,447, with depression: 5,671). }\end{array}$} \\
\hline
\end{tabular}

er countries ${ }^{2-4}$, but the adoption of unhealthy diet behaviors can be even higher among people with depression. This higher odds for the adoption of unhealthy diet can be due to the higher psycholog- ical suffering due to the COVID-19 quarantine ${ }^{8}$ as well as higher vulnerability ${ }^{7,13}$.

Previous studies found that people with depression present excessive energy intake, higher sugar 
and fat consumption when compared to healthy individuals ${ }^{14}$. Also, people with depression are more prone to consume sugary foods ${ }^{14-18}$. Considering the COVID-19 context and the higher vulnerability of people with mental disorders for psychological distress, a possible explanation can be through the association between higher perceived stress and food choices, in which people with higher stress tend to increase the consumption of sugary foods $s^{19,20}$. The similar increases in the low consumption of fruits or vegetables among participants with and without a previous diagnosis of depression reflect the already low prevalence of recommended consumption of fruit and vegetables before the pandemic ${ }^{18}$. A previous study also found that the consumption of fruits and vegetables was not associated with elevated depressive symptoms using the Brazilian National Health Survey ${ }^{18}$.

Contrary to our initial hypotheses that people with previous diagnosis of depression would present higher rates of physical inactivity and high TV-viewing incidence during the COVID-19 pandemic quarantine, we found that the incidence of both indicators was similar among participants with and without depression. We highlight that even with a similar incidence, people with previous diagnosis of depression presented higher physical inactivity before and during the COVID-19 pandemic, what is in line with previous studies ${ }^{6,21}$. In this sense, we emphasize the need for policies to stimulate physical activity and reductions in sedentary behaviors aiming to protect physical and mental health in both participants with and without depression considering the elevated incidence during the COVID-19 pandemic quarantine $e^{5,22}$.

Some limitations should be considered for the interpretations of our analyzes. Firstly, due to the web-based design, the present research had a low representativity of people with low socioeconomic conditions (without access to internet or electronic devices). The low participation of people with a low socioeconomic level can interfere in the representativeness of the sample even after adjusting for sample weights, taking into account a smaller group of participants representing proportionally more people from the general population. This representativeness bias (even if partly corrected by the sampling weights), can potentially be a problem taking into account that people of lower socioeconomic level had greater depressive symptoms and higher risk behaviors in the last Brazilian National Health Survey $(2013)^{12,23}$. Second, the recall bias should be considered for questionnaires and retrospective design. Third, the questionnaire only included if the participant had a lifetime diagnosis of depression, but the age at the diagnosis was not assessed. On the other hand, we presented data of more than 41,000 Brazilian adults (including 6,881 with previous diagnosis of depression), weighted for a nationally representativity, on health behaviors change during the quarantine due to the COVID-19 pandemic and we consider this as a strength.

To our knowledge, this was the first study that assessed the association between previous diagnoses of depression on changes of health behaviors during the COVID-19 pandemic quarantine. We conclude that participants with previous diagnosis of depression were at risk for incidence of unhealthy diet behaviors. Our study highlights the need for policies focusing on people with depression during the COVID-19 pandemic quarantine.

\section{Collaborations}

AO Werneck: Conceptualization, formal analysis and writing of the original draft. DR Silva: Conceptualization and writing of the original draft. PRB Souza-Júnior and LO Azevedo: Data curation, investigation and reviewing the first draft. DC Malta, MBA Barros and CL Szwarcwald: Conceptualization, project administration, methodology and reviewing of the first draft. All authors approved the submitted version.

\section{Acknowledgments}

This research received no specific grant from any funding agency in the public, commercial, or notfor-profit sectors. André Werneck is supported by the Fundação de Amparo à Pesquisa do Estado de São Paulo (FAPESP) with a PhD scholarship. Deborah C. Malta, Marilisa B. A. Barros and Célia L. Szwarcwald are supported by the Conselho Nacional de Desenvolvimento Científico e Tecnológico $(\mathrm{CNPq})$, which funded the productivity scholarship. This paper presents an independent research. The views expressed in this publication are those of the authors and not necessarily those of the acknowledged institutions. 


\section{References}

1. World Health Organization (WHO). Coronavirus Disease (COVID-19): Situation Report - 124. Geneva: WHO; 2020

2. Ammar A, Brach M, Trabelsi K, Chtourou H, Boukhris O, Masmoudi L, Bouaziz B, Bentlage E, How D, Ahmed M, Müller P, Müller N, Aloui A, Hammouda O, Paineiras-Domingos LL, Braakman-jansen A, Wrede C, Bastoni S, Pernambuco CS, Mataruna L, Taheri M, Irandoust K, Khacharem A, Bragazzi NL, Chamari K, Glenn JM, Bott NT, Gargouri F, Chaari L, Batatia H, Ali GM, Abdelkarim O, Jarraya M, Abed KE, Souissi N, Van Gemert-Pijnen L, Riemann BL, Riemann L, Moalla W, Gómez-Raja J, Epstein M, Sanderman R, Schulz SV, Jerg A, Al-Horani R, Mansi T, Jmail M, Barbosa F, Ferreira-Santos F, Šimunič B, Pišot R, Gaggioli A, Bailey SJ, Steinacker JM, Driss T, Hoekelmann A. Effects of COVID-19 Home Confinement on Eating Behaviour and Physical Activity: Results of the ECLBCOVID19 International Online Survey. Nutrients 2020; 12(6):1583.

3. Meyer J, McDowell C, Lansing J, Brower C, Smith L, Tully M, Herring M. Changes in physical activity and sedentary behaviour due to the COVID-19 outbreak and associations with mental health in 3,052 US adults. Cambridge Open Engage 2020. doi:10.33774/ coe-2020-h0b8g

4. Scarmozzino F, Visioli F. Covid-19 and the Subsequent Lockdown Modified Dietary Habits of Almost Half the Population in an Italian Sample. Foods 2020; 9(5):675.

5. Firth J, Siddiqi N, Koyanagi A, Siskind D, Rosenbaum S, Galletly C, Allan S, Caneo C, Carney R, Carvalho AF, Chatterton ML, Correll CU, Curtis J, Gaughran F, Heald A, Hoare E, Jackson SE, Kisely S, Lovell K, Maj M, McGorry PD, Mihalopoulos C, Myles H, O’Donoghue B, Pillinger T, Sarris J, Schuch FB, Shiers D, Smith L, Solmi M, Suetani S, Taylor J, Teasdale SB, Thornicroft G, Torous J, Usherwood T, Vancampfort D, Veronese N, Ward PB, Yung AR, Killackey E, Stubbs B. The Lancet Psychiatry Commission: a blueprint for protecting physical health in people with mental illness. Lancet Psychiatry 2019; 6(8):675-712.

6. Werneck AO, Vancampfort D, Oyeyemi AL, Szwarcwald CL, Stubbs B, Silva DR. Lifestyle behaviors among 4,343 Brazilian adults with severe mental illness and 55,859 general population controls: data from the Brazilian National Health Survey. Braz J Psychiatry 2020; 42(3):245-249.

7. Druss BG. Addressing the COVID-19 Pandemic in Populations With Serious Mental Illness. JAMA Psychiatry 2020; doi:10.1001/jamapsychiatry.2020.0894

8. Iasevoli F, Fornaro M, D'Urso G, Galletta D, Casella C, Paternoster M, Buccelli C, de Bartolomeis A, the COVID-19 in Psychiatry Study Group. Psychological distress in patients with serious mental illness during the COVID-19 outbreak and one-month mass quarantine in Italy. Psychol Med 2020; 1-3. doi:10.1017/ S0033291720001841

9. World Health Organization (WHO). Global Recommendations on Physical Activity for Health. Geneva: WHO; 2010.

10. Monteiro CA, Cannon G, Lawrence M, Louzada MLC, Machado PP. Ultra-Processed Foods, Diet Quality, and Health Using the NOVA Classification System. Rome: Food and Agriculture Organization of the United Nations - FAO; 2019.
11. Gardner MJ, Altman DG. Confidence intervals rather than P values: estimation rather than hypothesis testing. BMJ 1986; 292(6522):746-750.

12. Munhoz TN, Nunes BP, Wehrmeister FC, Santos IS, Matijasevich A. A nationwide population-based study of depression in Brazil. J Affect Disord 2016; 192:226233.

13. Correa H, Malloy-Diniz LF, Silva AG. Why psychiatric treatment must not be neglected during the COVID-19 pandemic. Braz J Psychiatry 2020; 42(4):449.

14. Firth J, Stubbs B, Teasdale SB, Ward PB, Veronese N, Shivappa N, Hebert JR, Berk M, Yung AR, Sarris J. Diet as a hot topic in psychiatry: a population scale study of nutritional intake and inflammatory potential in severe mental illness. World Psychiatr 2018; 17(3):365367.

15. Gibson-Smith D, Bot M, Brouwer IA, Visser M, Penninx BWJH. Diet quality in persons with and without depressive and anxiety disorders. J Psychiatr Res 2018; 106:1-7.

16. Gibson-Smith D, Bot M, Brouwer IA, Visser M, Giltay EJ, Penninx BWJH. Association of food groups with depression and anxiety disorders. Eur J Nutr. 2020; 59(2):767-778

17. Saghafian F, Malmir H, Saneei P, Keshteli AH, Hosseinzadeh-Attar MJ, Afshar H, Siassi F, Esmaillzadeh A, Adibi P. Consumption of fruit and vegetables in relation with psychological disorders in Iranian adults. Eur J Nutr 2018; 57(6):2295-2306.

18. Sousa KT, Marques ES, Levy RB, Azeredo CM. Food consumption and depression among Brazilian adults: results from the Brazilian National Health Survey, 2013. Cad Saude Publica 2020; 36(1):e00245818.

19. Errisuriz VL, Pasch KE, Perry CL. Perceived stress and dietary choices: The moderating role of stress management. Eat Behav 2016; 22:211-216.

20. Oliver G, Wardle J. Perceived Effects of Stress on Food Choice. Physiol Behav 1999; 66(3):511-515.

21. Vancampfort D, Firth J, Schuch FB, Rosenbaum S, Mugisha J, Hallgren M, Probst M, Ward PB, Gaughran F, De Hert M, Carvalho AF, Stubbs B. Sedentary behavior and physical activity levels in people with schizophrenia, bipolar disorder and major depressive disorder: a global systematic review and meta-analysis. World Psychiatry 2017; 16(3):308-315.

22. Sallis JF, Adlakha D, Oyeyemi A, Salvo D. An international physical activity and public health research agenda to inform coronavirus disease- 19 policies and practices. J Sport Health Sci 2020; 9(4):328-334.

23. Malta DC, Andrade SSCA, Stopa SR, Pereira CA, Szwarcwald CL, Silva Júnior JB, Reis AAC. Brazilian lifestyles: National Health Survey results, 2013. Epidemiologia e Serviços de Saúde 2015; 24(2):217-226.
Article submitted 13/07/2020

Approved 28/07/2020

Final version submitted 30/07/2020 